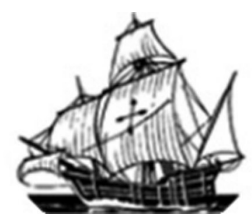

\title{
Entre inferno e sertão: discutindo os espaços construídos na literatura de cordel
}

\author{
André Ricardo Nunes Nascimento ${ }^{1}$
}

\begin{abstract}
Resumo: Neste artigo pretende-se analisar, traçando comparações, as representações dos espaços do Sertão e do Inferno, elementos esses encontrados nas narrativas dos folhetos A chegada de Lampião no Inferno, de José Pacheco, e Peleja de Manoel Riachão com o Diabo, de Leandro Gomes de Barros. Os folhetos supracitados trazem pelejas do Diabo com os moradores do Sertão e também deixam transparecer que apetrechos de identificação desses espaços se tecem nas linhas das obras. Nessa conjuntura, a religiosidade popular se encena como fator religioso preponderante e arraigado no interior dessas narrativas, pois o Diabo, ao "pelejar" com os personagens do sertão, é vencido por não resistir às artimanhas de entidades como Nossa Senhora, santos e beatos, que representam a imagem de Deus e suas forças. Para a tessitura desse trabalho, utiliza-se como aporte teórico: Santos (2007), diferenciando espaço e território da cultura; Balandier (1976), para a discussão de tradição e continuidade cultural, pelo viés das dinâmicas sociais; Albuquerque Jr. (1999), que traz a invenção do Nordeste num contexto literário; dentre outros. Adota-se como método a análise comparativa para demonstrar que os preceitos cristãos estão bastante enraizados no cotidiano nordestino e que as características presentes na composição do Inferno cristão se misturam com as peculiaridades do Sertão brasileiro, causando um processo de simbiose religiosa e cultural, que engendra a caracterização da coragem e resistência do sertanejo, frente às adversidades rotineiras da vida. Nessa perspectiva, as manifestações e valores e crenças dos sertanejos são expostas e contribuem para a constituição do mosaico cultural do Brasil.
\end{abstract}

Palavras-chave: diabo; sertão; inferno; religiosidade; popular.

\begin{abstract}
In this paper we intend to analyze, tracing comparisons, representations of spaces of the Hinterland and Hell, these elements found in the narratives of flyers A Chegada de Lampião no Inferno, of José Pacheco, and Peleja Manoel Riachão com o Diabo, the Leandro Gomes de Barros. The flyers above contentions bring the Devil with the residents of the Hinterland and also betray accoutrements that identification of these spaces are woven lines of works. At this juncture, the popular religiosity is staged as a religious factor predominates and ingrained within these narratives, as the Devil, the " battle " with the characters of the interior, is overcome not stand against the wiles of entities such as Virgin, saints and blessed, representing the image of God and his forces. To the fabric of this work, we use as theoretical : Santos (2007), differing cultural space and territory; Balandier (1976 ), for discussion of tradition and cultural continuity, by the bias of social dynamics; Albuquerque Jr. (1999), which brings the invention of the Northeast in literary context, among others. Adopted as the comparative analysis method to demonstrate that the Christian precepts are very rooted in the daily Northeastern and features present in the composition of Hell Christian mingle with the

\footnotetext{
${ }^{1}$ Aluno do Curso de Mestrado do Programa de Pós Graduação em Crítica Cultural da Universidade do Estado da Bahia - UNEB. (r1.andre.3@gmail.com)
} 
peculiarities of the Brazilian backlands, causing a process of religious and cultural symbiosis, which engenders characterization of the courage and endurance of the backcountry, the face of adversity routine life. In this perspective, the demonstrations and the values and beliefs of the hinterland are exposed and contribute to the formation of the cultural mosaic of Brazil.

Keywords: devil, hinterland; hell; religiosity; popular.

\section{Introdução}

O Brasil, em seu contexto cultural, é representado por inúmeras manifestações que contribuem para um enriquecimento de seu povo, que de acordo com suas próprias vivências cria e recria seus entornos culturais. Tendo sua maior representação no Nordeste brasileiro a Literatura de Cordel apresenta-se como importante expressão e dela ramificam-se vários aspectos que demonstram as singularidades das narrativas populares construídas no Sertão.

Essa literatura, originária do seio das construções populares, cria e transforma territórios que deixam nítidos elementos perpetuadores dos medos, coragens, angústias, alegrias e sofrimentos dos sertanejos. Nesse sentido, as discussões desse artigo enfocam o Sertão e o Inferno, espaços construídos dentro e fora do imaginário nordestino, mas que delineiam parte das narrativas que se tecem no solo de sua cultura.

Inferno e Sertão, numa leitura dos Sertanejos e daqueles que transmitem suas impressões acerca do entrelaçar desses espaços, configuram, na Literatura de Cordel, aspectos de aproximações e distanciamentos. Algumas narrativas descrevem o inferno como local de sofrimento, seca e temperaturas quentes associando-o ao Sertão brasileiro, lugar onde se construiu o ideário de representação com parte dessas mesmas características, sendo algumas delas evidenciadas por questões geográficas e climáticas.

Nesse entremeio, podendo-se fazer interseções entre esses espaços, temos diversos folhetos de Cordel que travam, no interior de seus versos e rimas, pelejas onde os moradores do Sertão duelam contra os moradores do Inferno, sendo representados por figuras míticas e pessoas comuns e o Diabo, respectivamente.

Para a construção desse artigo, analisaram-se, traçando comparações, as representações dos espaços do Sertão e do Inferno nas narrativas dos folhetos $A$ chegada de 
Lampião no Inferno, de José Pacheco ${ }^{2}$, e Peleja de Manoel Riachão com o Diabo, de Leandro Gomes de Barros ${ }^{3}$. Para a tessitura do mesmo, utiliza-se como aporte teórico: Santos (2007), diferenciando espaço e território da cultura; Balandier (1976), para a discussão de tradição e continuidade cultural, pelo viés das dinâmicas sociais; Albuquerque Jr. (1999), que traz a invenção do Nordeste num contexto literário; dente outros.

Esses espaços se costuram em meio às criações populares. Muitas vezes ganham novas interpretações ou contribuem para estereótipos que se consolidam e acabam que estigmatizando determinado elemento como fator predominante em um espaço, como é a dessa associação entre Inferno e Sertão, trazendo para esse último, aspectos do primeiro, contribuindo assim para a consolidação do preconceito regional, cultural e intelectual dos moradores do Nordeste, região onde se concentra a maior parte do Sertão brasileiro.

\section{O Inferno e suas comparações com o Sertão: uma construção histórico-popular}

No nordeste brasileiro, a religião que predomina é o catolicismo, mesmo com o avanço das igrejas pentecostais, estando presente tanto no interior, quanto nas capitais nordestinas grandes números de fies e Igrejas. Historicamente, os preceitos religiosos atrelados ao catolicismo cresceram e seus dogmas e construções absolvidos pelos seus seguidores. Nesse sentido, as representações do Inferno ganham consistência e povoam o imaginário dos sertanejos.

Sendo encontrado nos escritos bíblicos, o Inferno é utilizado como espaço de reforço da crença do Diabo. Nessa conjuntura, ele seria a consequência para os humanos, por não terem obedecido a tudo que Deus ensinou. A ideia de maniqueísmo se reforça nessa crença cristã.

\footnotetext{
${ }^{2}$ José Pacheco, pernambucano residindo algum tempo na cidade de Caruaru, naquele mesmo estado. Seus folhetos mais importantes são História da princesa Rosamunda ou a morte do gigante e $A$ chegada de Lampião no inferno. As histórias de gracejos são um dos aspectos marcantes dos cordéis de José Pacheco, considerado um dos maiores cordelistas satíricos do Brasil. (http://www.casaruibarbosa.gov.br). Acesso em 23 ago. 2010.

${ }^{3}$ Leandro Gomes de Barros, paraibano nascido em 19/11/1865. Foi um dos poucos poetas populares a viver unicamente de suas histórias rimadas, que foram centenas. Leandro versejou sobre todos os temas, sempre com muito senso de humor. Começou a escrever seus folhetos em 1889. (http://www.casaruibarbosa.gov.br). Acesso em 23 ago. 2010.
} 
Mas o Inferno não é uma criação basicamente cristã. A palavra, usada por inúmeras mitologias e filosofias, origina-se do Latim Infernum, e seu significado equivale a mundo inferior ou às profundezas; lugar preparado por Deus para servir como prisão à Satanás e àqueles que, em vida, não tiveram uma boa conduta.

Dentre as crenças de Inferno criadas na história antiga, destaca-se a grega, esta se embasa nas crenças do local chamado Hades. O dicionário grego do Novo Testamento de Strong diz que Hades é o lugar (estado) das almas. [...] O Hades é tecnicamente o mundo invisível, o Seol Hebreu, a terra dos mortos ${ }^{4}$.

Segundo a doutrina cristã, os que não obedecerem aos preceitos bíblicos serão lançados no abismo, a morada dos mortos, restando-lhe o sofrimento eterno:

Ele agarrou o Dragão, que é o Diabo, Satanás. Acorrentou o Dragão por mil anos, e o jogou dentro do Abismo. [...] E cada um foi julgado de acordo com a sua conduta. A morte e a morada dos mortos foram, então, jogados no lago de fogo. (APOCALIPSE: 20: 2 e 3: 13 e 14).

O trecho supracitado, além de enfatizar o Diabo como Dragão, mostra o lago de fogo, denominação respaldada nos princípios cristãos que têm este espaço como o lugar reservado aos malfeitores, o castigo celeste para os maus. Os seguidores do cristianismo temem obter como recompensa a morada ao lado do Diabo, o que significa sofrer pagando por seus pecados.

No âmbito dessa construção, o Inferno é visto, sob os dogmas cristãos, como um espaço onde toda a maldade vinda do mundo se junta; ali queimará eternamente num fogo tão árduo quanto o sofrimento causado por quem nele reside. Segundo essa crença, quem uma vez habita esse lugar dele jamais sairá e ali queimará no fogo eterno: [...] "Afastem-se de mim, malditos. Vão para o fogo eterno, preparado para o diabo e seus anjos [...] (MATEUS, 25: 41).

Não só o cristianismo teme este lugar, outras religiões também têm a criação de um espaço reservado àqueles de má conduta e, assim sendo, criou-se um arquétipo do Inferno, quando se podem citar diversos povos que têm denominações e visões diferentes deste ambiente.

\footnotetext{
${ }^{4}$ Disponível em: http://www.estudosgospel.com.br/estudos/diversos/inferno-seol-hades-gehena-tartaro.html Acesso 12 fev. 2012.
} 
A mitologia grega chama o Inferno de Tártaro, o reino de $H_{a d e s}{ }^{5}$, para onde vão os mortos; no Judaísmo, esse local chama-se Gehinom ou Gehena, o espaço reservado à purificação das almas e, ao contrário do cristianismo, a estada nesse âmbito não é eterna; no Islamismo, o Inferno é eterno e seus adeptos o veem ambientado em sete portões que servem de entrada para as mais distintas classes de condenados; no Budismo, esse local é visto como o de maior sofrimento onde menos há possibilidades de libertação.

No folheto A chegada de Lampião no Inferno, o Inferno é invadido por um sertanejo, representado pela imagem de Lampião. Seus versos mostram o inferno sendo posto em desordem:

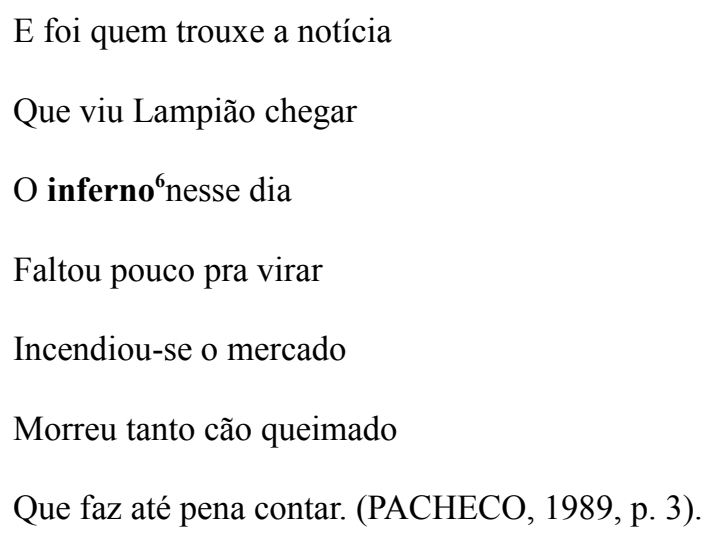

A septilha supracitada, e por Lampião ter uma conduta não pautada nos princípios do "Bem" cristão, o personagem nordestino é colocado no Inferno, ao encontro do Diabo. Recheados de resquícios humorísticos, os versos analisados remetem a ousadia, coragem e força de um morador do Sertão, a caracterizar os prejuízos causados no território do principal arqui-inimigo de Deus, sujeito esse tão danado que toca fogo no Inferno.

Para que haja concretude nas crenças de Inferno é necessário a existência do Diabo, que representa o Mal, e seu adversário, que se consolida na imagem de Deus. Nesse contexto, podemos inferir que o autor coloca a personagem sertaneja com forças capazes de conturbar as estruturas do local de estada do Diabo, dando a aquele uma nomenclatura que possibilite a derrocada deste.

\footnotetext{
${ }^{5} \mathrm{Na}$ mitologia grega, Hades era o deus dos infernos. ${ }^{6}$ Grifo nosso.

Disponível em: http://www.suapesquisa.com/mitologiagrega/hades.htm Acesso 27 fev. 2012.
} 
Desse modo, há uma elevação, mesmo que negativa, da imagem representativa do morador do Sertão, que se mostra com forças capazes de atormentar e até vencer o principal adversário de Deus. Ou seja, ele tem todos os apetrechos de inteligência e coragem, cabendo a ele direcionar suas forças para o bem ou o mal. Essa elevação pode ser associada e colocada em detrimento ao preconceito regionalista construído e propagado contra o Nordeste brasileiro. Os versos vêm colocar os moradores dessa região com sagacidade suficiente para a derrocada do Diabo.

Sobre o preconceito regionalista pode-se constatar que o mesmo é uma produção construída. Colocar a personagem Lampião em evidência e proporcionar sua vitória no Inferno e contra o Diabo e seu exército é uma forma de desconstrução desse preconceito, ou até mesmo acentuá-lo.

Inventando-se tradições para a consolidação do mosaico cultural brasileiro, o Nordeste ficou com a parte repleta de cicatrizes que se estendeu entre essas construções e a realidade vivenciada pelos Nordestinos. Sobre essa invenção Albuquerque Jr. em a Invenção do Nordeste e Outras Artes relata:

\begin{abstract}
A busca das verdadeiras raízes regionais, no campo da cultura, leva à necessidade de inventar uma tradição. Inventando tradições tenta-se estabelecer um equilíbrio entre a nova ordem e a interior; busca-se conciliar a nova territorialidade com antigos territórios sociais e existenciais. A manutenção de tradições é, na verdade, sua invenção para novos fins, ou seja, a garantia da perpetuação de privilégios e lugares sociais ameaçados. (ALBUQUERQUE JUNIOR, 2011, p. 90).
\end{abstract}

Nesse contexto, o Nordeste em sua configuração territorial, ganha essa representação de desprivilégio. A imagem de Inferno trazida pelo folheto é colocada, estrategicamente, como o espaço de embate para demonstrar que a personagem do Sertão torna-se vitoriosa em um local onde as características são efetivamente construídas como mais aguçadas que a do Sertão, mas mesmo assim ela desestrutura o território do maligno.

Sair deste espaço de invenção de tradições é essencial para a formação de uma identidade nordestina diferente daquela de lugar social de ameaças. Perceber as qualidades do nordestino retirando-o daquela pintura onde o mesmo é desenhado como coitado torna-se fundamental para a efetivação de um ideário sem preconceitos. 
No folheto Peleja de Manoel Riachão com o Diabo, há mais uma peleja de um morador do Sertão contra o Diabo. Dessa vez um tocador de viola trava um embate discursivo contra o Satanás. Nota-se, em uma de suas estrofes, o preconceito cultural e intelectual contra um sertanejo:

\author{
Negro: ${ }^{7}$ Eu sou livre como o vento \\ A minha linhagem é nobre; \\ Sou um dos mais ilustrados \\ Que o sol neste mundo cobre - \\ Nasci dentro da grandeza \\ Não saí de raça pobre! (BARROS, [s.d.], p. 05).
}

Na sextilha supracitada, temos um diálogo em que o Diabo, denominado no cordel como Negro, se refere ao Nordestino Manoel Riachão. Em seu discurso, aquele se expressa com grandeza em relação ao Sertanejo, dizendo não ser de classe pobre, isso em detrimento ao discurso de seu adversário.

Percebe-se também que os cordéis, às vezes, colocam-se como perpetuadores do preconceito, fato evidenciado pelo verso supracitado, onde o Diabo é colocado como Negro, aquele que só serve para o mal. Nesse contexto, e em análise do desenho de capa do folheto da personagem de Manoel Riachão, percebe-se que o mesmo configura-se como um cantador de versos, pessoa simples que com seu chapéu demonstra trejeitos de sertanejo:

\footnotetext{
${ }^{7}$ Grifo do autor.
}

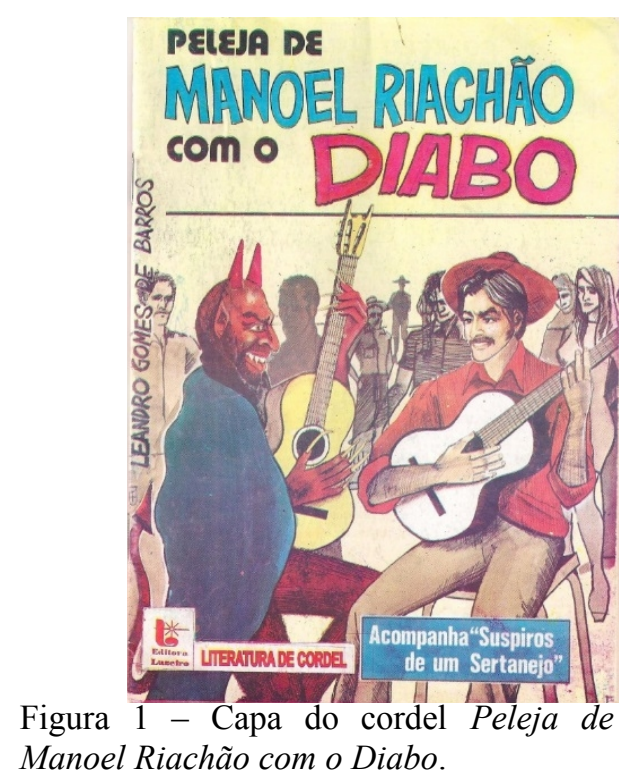


Nessa perspectiva, o Diabo colocar-se superior a Manoel Riachão, não no sentido da peleja, mas sim na configuração de sua própria confiança pode ser apresentado como um fator de preconceito. O Diabo, na ficção do folheto coloca-se superior, mas trazendo essa representação para a realidade é comum encontrar pessoas que se colocam superiores aos outros por essas nascerem ou residirem no Nordeste.

Albuquerque Junior faz interessantes posicionamentos sobre esse preconceito regional existente no Brasil, situando-o na região Nordeste. Em seus estudos ele aponta que as artes produzidas dentro e fora do Nordeste acabaram que perpetuando essa imagem de inferioridade deste em relação às outras regiões. Segundo ele, o Sertão nordestino sofreu também um processo de generalização dos distanciamentos das sociedades, consideradas pelos produtores dessas artes como civilizadas:

\begin{abstract}
A relação entre o sertão e a civilização é sempre ancorada como excludente. É um espaço visto como repositório de cultura folclórica, tradicional, base para o estabelecimento da cultura nacional. [...] a civilização deveria, no entanto, ser levada ao sertão, resgatando essa cultura e essas populações que aí viviam. Lobato, em Urupês, uma das primeiras obras a contestar o regionalismo literário falso e exótico, das primeiras décadas do século, procura focalizar momentos da vida social do interior, com ironia, com sarcasmo, criticando a falta de políticas de modernização do interior do país, embora desacredite da própria capacidade desses homens pobres, vistos como, por natureza, preguiçosos, indolentes, sem iniciativa. Só uma vanguarda modernizadora podia recuperar o sertão para a civilização nacional, não importada da Europa. (2011, p. 68).
\end{abstract}

O autor aponta que a produção de algumas literaturas, como as de Monteiro Lobato, e outros autores pós-30 contribuíram para o restante do país conceber o Sertão com uma visão estigmatizada pela ideia de inferioridade. $\mathrm{O}$ que se produziu aqui demostrou uma cultura com bases num tradicionalismo que enquadrava os nordestinos numa pintura de limitações.

Moacir dos Anjos, em suas Vinte notas sobre identidade cultural no nordeste do Brasil, demonstra que essas construções artísticas não se ergueram num propósito de demarcar o nordestino com produto de seus problemas político-sociais e geográficos. Essa relação se expõe e ganha forma pelas interpretações que se ramificaram e ganharam forma em visões de fora do Nordeste: 
A construção dessa visualidade esteve desde o início, entretanto, eivada de interpretações conflituosas sobre o repertório de imagens que efetivamente distinguiriam simbolicamente o Nordeste: se alguns artistas assumiam, em seus trabalhos, um tom celebratório de cores, formas e gentes encontráveis naquele espaço, outros utilizavam imagens e cenas comuns da região como índices das precárias condições de vida de seus habitantes. (DOS ANJOS, acesso em julho de 2013).

Percebe-se, então, que fartas são as imagens do Nordeste que tendenciam visões pelo viés do preconceito. Nesse aspecto, os cordéis trazerem o Inferno e a imagem do Diabo para dentro de suas narrativas pela via contrária às construções que contribuem para o processo de esteriotipização. Eles colocam as personagens sertanejas como vitoriosas perante a principal força de representação do mal, ou seja, trazem esses personagens marcados pelas cicatrizes da seca e da má distribuição de renda, mas que driblam esses problemas e ainda encontram forças para provocar a derrocada do Diabo, além de enfrentar, no caso de Lampião, as intempéries do Inferno.

\section{O Sertão e suas marcas: um território de construções}

Cada indivíduo pertence a um território e dele absorve as características que vão permear suas identidades e os modos com que outros sujeitos, não residentes naquele espaço, os perceberão. Os moradores do Sertão, a exemplo, têm características que os demarcam como pertencentes a esse espaço como, a exemplo, a linguagem e o vestuário.

É notório que o Sertão, espaço social recheado de singularidades, tem relações de significação diretamente ligadas à vida das pessoas e acaba que interferindo nas representações que essas exprimem fora desse contexto. Nesse sentido, os cordéis analisados colocam em destaque, não essas características, mas sim os moradores do Sertão numa representação que pincela a territorialidade como fator paisagístico, ou seja, as características geográficas e a imposição de alguns distanciamentos estão ali, mas isso não vai interferir na capacidade intelectual daqueles que ali residem:

A territorialização da paisagem, isto é, o reconhecimento de que cada território se manifesta paisagisticamente em uma fisionomia singular, dinâmica e em plurais imagens sociais, faz da paisagem um aspecto importante da qualidade de vida da população, porque a paisagem é, antes de tudo, resultado da relação sensível das pessoas com o seu entorno percebido, cotidiano ou visitado. Por isso mesmo, a paisagem é também elemento de afinidade e identidade territorial, e manifestação da diversidade do espaço geográfico que se faz explícita na materialidade de cada paisagem e suas representações sociais. (MATA, 2006, p. 18). 
Para a configuração das narrativas dos folhetos a sagacidade dos sertanejos é o fator que permeia os embates traçados, e não as dificuldades enfrentadas por eles ou as imposições climáticas ou regionais, pelo contrário, o que ocorre é a demonstração de força e coragem dos nordestinos, que mesmo enfrentado algumas adversidades ainda conseguem reunir elementos para derrotar o instrumental maligno, como no caso de Manoel Riachão em sua visão ao afinar a viola. Esse personagem vê no Diabo um oponente tão fácil de ser derrotado que, dentro de sua auto estima enquanto cantador, não há a necessidade de grandes feitos para derrota-lo.

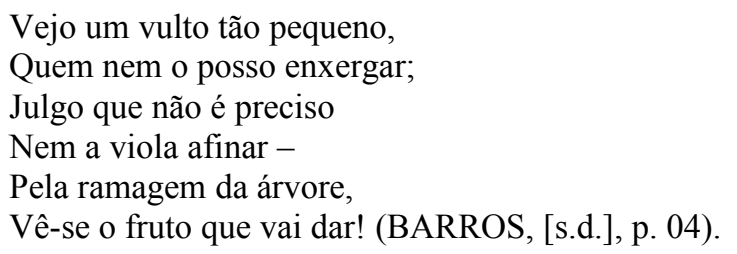

Nesses versos, percebe-se que a personagem do Sertão considera-se superior a imagem do Diabo - desconstrução do preconceito - nessas linhas eles saem da quietude em que estão acostumados a viver e buscam formas, até mesmo por intermédio de Deus, de melhorar sua vida e mostrarem-se superiores as forças maléficas, como narra o cordel de Leandro Gomes de Barros:

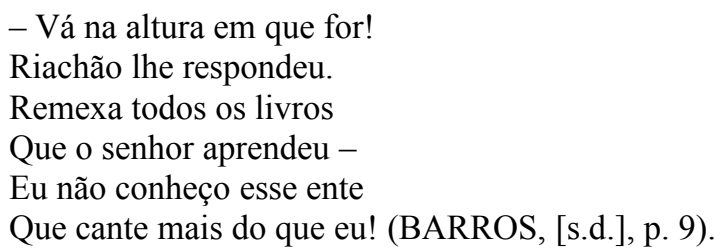

O desejo de o Diabo arrebanhar almas, e a coragem e a confiança do nordestino criam pelejas em que os personagens principais usam todos os artifícios para conseguir a vitória. Nessa conjuntura, o sertanejo passa a duelar com o Demônio para alcançar seus objetivos:

Assimilando a nova filosofia de vida, o personagem se dispõe a dar qualquer passo
[...]. Negociará com o Demônio e não vacilará [...] Além de sentir-se a vontade para
rir de tudo isso o homem experimenta a tentação de apoderar-se do instrumental
demoníaco e utilizá-lo com outras finalidades. (PONTES, 1979, p. 36).

As histórias do personagem Manoel Riachão reforçam a coragem do nordestino que, ao enfrentar o Demônio, coloca-se disposto a vencê-lo. Ao conseguir, vê-se repleto de felicidade por derrotar o principal adversário de Deus e do próprio homem. 
As narrativas de Leandro Gomes de Barros expressam o quanto o nordestino é inteligente, mas mostra também que ele só consegue vencer o Diabo, pela fé e confiança em Deus, o que torna a demonstrar que em alguns aspectos e obedecendo a tradições, esse cordel mostra o quanto o nordestino é competente, mas também coloca que sua força é advinda de Deus, colocando-o novamente como um sujeito frágil. Nesse aspecto, é interessante salientar que o fato de os sertanejos terem sido colocados como inferiores obedeceu uma tradição e dela se ramificou as impressões tidas sobre o espaço sertanejo-nordestino.

Muitas tradições, como diz Balandier em seu texto As dinâmicas sociais: sentido e poder, advém de fatores que determinam o modo como serão vistos os valores e representações de áreas distintas da sociedade, regulando assim formas de percepções internas e externas. No caso do estereótipo construído sobre o Nordeste, pode-se associar a consolidação de uma tradição que ditou as formas culturais e sociais de concebimento:

\begin{abstract}
A tradição pode ser vista como prática social e reguladora das condutas. Vivida sob esse aspecto, toma-se tradicionalismo. Sua função é suscitar a conformidade, conservar, do melhor modo possivel, a "repetição" das formas sociais e culturais. Por fim, a tradição pode ser vista como determinante, quer de um tipo de sociedade global, quer de determinados sistemas de relações no bojo dessa sociedade. Qualifica, assim, o tipo ideal chamado "sociedade tradicional", ou os setores ditos "tradicionais" de uma sociedade que, globalmente, não se harmoniza com o tipo mencionado. (BALANDIER, 1976. p.100).
\end{abstract}

Nesse sentido, essa "tradição nordestina" acaba que reafirmando a ideia de invenção construída nessa região, até mesmo como forma de controle social, no sentido de hierarquizar uma região em detrimento a outra. Assim, cruzando essas informações sobre tradição com as vertentes levantadas por Albuquerque Junior, pode-se dizer que o espaço sertanejo-nordestino foi construído por vieses e conjuntos: “O Nordeste, assim como o Brasil, não são recortes naturais, políticos ou econômicos apenas, mas, principalmente, construções imagéticodiscursivas, constelações de sentido.” (2011, p.307).

O Nordeste, como aponta o autor, é fruto de constelações e discursos que se embebem, principalmente, pela falta de chuva em parte dessa região. Nesse construto, a seca é colocada como fator de propagações e ideologias que se aproveitam desse aspecto para fazer do Sertão Nordestino um espaço propício para se tirar proveitos políticos, sociais e econômicos. É no período eleitoreiro que esse oportunismo mais se apresenta, nele são prometidas soluções que se derrocam após a eleição, tornando a acontecer ou em dois ou quatro anos depois.

Isso se deve a uma apropriação artística, que vê, nas características da seca, um espaço amplo de aquisição de matérias-primas, muitas vezes imagéticas, para a formação de muitas 
obras que versam sobre essa região. O contexto dos folhetos analisados traz esses mesmos vestígios, mas numa vertente que permite reconhecer que esses elementos ali estão, mas não vão interferir na conduta ou segregação intelectual ou social do sujeito que ali reside. Isso se torna perceptível no verso de Leandro Gomes de Barros:

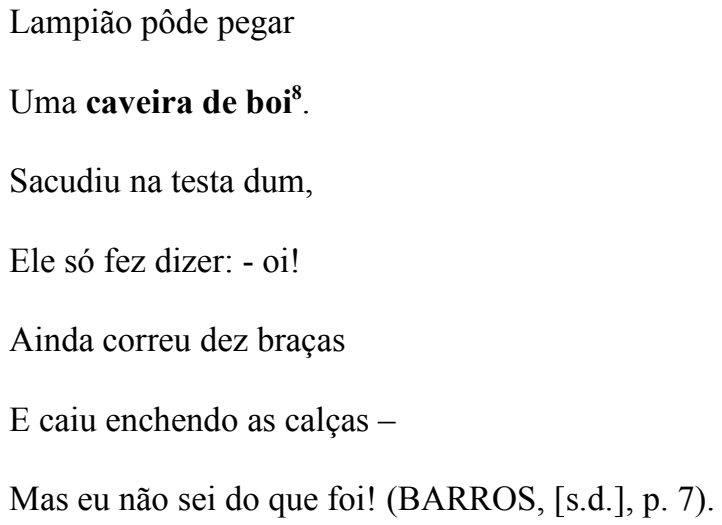

A caveira de boi, característica catalisada pela estrofe e associada rapidamente ao Sertão, ditos por muito como seco, remete a uma imagem bastante presente nas construções pautadas na problemática da seca. Ela representa um estado de falta de chuva, em que o nordestino vê seu sofrimento evidenciado pela perda de seu rebanho, onde é de fácil encontro, pelos caminhos e vales perpetuados pela aridez da terra, a caveira do boi.

O Sertão nordestino, em seu espaço repleto de características próprias, por assim ser, não deixa de compor os aspectos identitários dos sujeitos ali residentes. Como Diz Milton Santos (2007), todos os indivíduos têm entrelaçamentos, quer de identificação, quer simbólicos, com o território em que convivem ou pertencem:

O território em que vivemos é mais que um simples conjunto de objetos, mediante os quais trabalhamos, circulamos, moramos, mas também um dado simbólico.[...] sem o qual não se pode falar em territorialidade. Esta não provém do simples fato de viver num lugar, mas da comunhão em que com ele mantemos. (SANTOS, 2007, p. 82).

Essa territorialidade, citada pelo autor, nos mostra que a relação entre o território e o sujeito que nele reside é bastante interligada. Nesse contexto, e numa leitura das narrativas que os folhetos apresentam pode-se inferir a impossibilidade de distanciamentos de um

\footnotetext{
${ }^{8}$ Grifo nosso!
} 
elemento do outro, ou seja, o sujeito não pode se desvencilhar das nuances do lugar em que nasceu ou que residiu.

Se não se pode afastá-los, no entorno de suas características, deve-se, para a desconstrução do preconceito, reconhecer que os fatores de aproximação existem e tem sua importância na identidade das pessoas. No entanto, estigmatizar um local como perpetuador de importâncias culturais e intelectuais é pratica do preconceito, o que os folhetos, com a elevação dos personagens nordestinos, tentam exumar.

Assim, vê-se que a cultura, por si só, cria mecanismos em que colocam os construtos humanos em declínio. A Literatura de Cordel, nesse sentido, desconstrói a invenção de Nordeste como região inferior ou de moradores de possibilidades intelectuais baixas. Ela, tecendo narrativas com algumas características religiosas, faz uma elevação da imagem dos sertanejos, em detrimento ao preconceito que se perpetua pelos corredores da história nacional.

As dinâmicas culturais são colocadas como as responsáveis pelas desconstruções de alguns dos produtos criados pelo homem, ou seja, a cultura é um campo bastante complexo que não pode ser manipulado, a cultura é composta por multiplicidades com ramificações que as barreiras do homem não conseguem controlar. Sobre o campo da cultura e sobre a relação desta com os produtos humanos, Teixeira Coelho posiciona-se:

A cultura não é mais o campo que o homem prepara e do qual extrai uma série de produtos; não é nem o arado que trabalha esse campo, não é nem mesmo o conjunto dessas coisas todas mas é preferencialmente a lâmina afiada que penetra nesse campo e o corta e revolve, pondo para cima o que estava embaixo e vice-versa. (COELHO, 2008, p. 36).

Na perspectiva de elevação, tanto de Lampião, quanto de Manoel Riachão, essa lâmina afiada, trazida pelo autor, contribuiu para essa reviravolta que permeou novas interpretações para narrativas construídas nos espaços do Sertão e do Inferno. Nelas, ficou evidente a sagacidade e coragem do Nordestino, frente à entidade de maior representação do mal. Nesse sentido, derrotar o Diabo dentro e fora de seu espaço, significa também vencer estereótipos construídos contra o Sertanejo. 


\section{Referências}

ALBUQERQUE JR, Durval Muniz. A Invenção do Nordeste e Outras Artes. 3. ed. São Paulo: Cortez, 2011.

BALANDIER, Georges. As dinâmicas sociais: sentido e poder. São Paulo: DIFEL, 1976.

BARROS, Leandro Gomes. Peleja de Manoel Riachão com o Diabo. São Paulo, Luzeiro, [s.d.]

BÍBLIA. Português. Bíblia Sagrada. Tradução de Ivo Stomiolo e Euclides Martins Balacin. São Paulo: Edição Pastoral, Paulus, 1990.

COELHO, Teixeira. A cultura e seu contrário: cultura arte e política pós-2001. São Paulo: Itaú Cultural, 2008.

MATA, Rafael. Um concepto de paisaje para la gestión sostenible del territorio. In: MATA, R.; TAROJA, Alexandre. (coords.). El paisaje y la gestiõn del territorio: critérios paisajísticos em la ordenación del territorio. Barcelona: Diputació de Barcelona, 2006.

DOS ANJOS, Moacir. Vinte notas sobre a identidade cultural no Nordeste do Brasil, acesso

Julho de 2013.

(http://portalmultirio.rio.rj.gov.br/sec21/chave_artigo.asp?cod_artigo=1039)

PACHECO, José. A chegada de Lampião ao Inferno. [s. 1.]: Luzeiro. 1988.

PONTES, Mario. Doce como o Diabo: o demônio na literatura de cordel. Rio de Janeiro, Codecri. 1979.

SANTOS, Milton. O Espaço do Cidadão. São Paulo: Edusp, 2007. 